\title{
KNOWLEDGE, ATTITUDE AND PRACTICE OF EMERGENCY CONTRACEPTION AMONGST HEALTHCARE WORKERS IN IDP CAMPS AND HOST COMMUNITY CLINICS IN JERE AND MAIDUGURI METROPOLITAN LOCAL GOVERNMENT AREAS, BORNO STATE, NIGERIA
}

\author{
${ }^{1}$ Babagana Bako, ${ }^{2}$ Bala Mohammed Audu, ${ }^{3}$ Mohammed Bello Kawuwa, ${ }^{4}$ Asta Mana, ${ }^{4}$ Anna Peter
}

${ }^{1}$ Department of Obstetrics and Gynaecology, College of Medical Sciences, Gombe State University, Gombe. ${ }^{2}$ Department of Obstetrics and Gynaecology, College of Medical Sciences, Abubakar Tafawa Balewa University, Bauchi

${ }^{3}$ Department of Obstetrics and Gynaecology, College of Medical Sciences, University of Maiduguri, Maiduguri. ${ }^{4}$ Department of Obstetrics and Gynaecology,

University of Maiduguri Teaching Hospital, Maiduguri

Correspondence and reprint request to: Professor Babagana Bako, Department of Obstetrics and Gynaecology, College of Medical Sciences, Gombe State University, Gombe.

Email: babaganabako@gsu.edu.ng Phone: +23435997255

\begin{abstract}
Background: Emergency contraception (EC) offers women a second chance to avoid unintended pregnancy after unprotected sexual intercourse. Besides its availability, requisite knowledge and positive attitude of the healthcare works will encourage its utilization by the Internally Displaced Persons (IDP) and host community. Objectives To determine the knowledge, attitude and practice of EC by healthcare workers (HCWs) in IDP camps and host community clinics in Jere and Maiduguri metropolitan local government areas (LGAs) of Borno state, Nigeria. Methodology: Self-administered questionnaires were issued to HCWs attending a workshop on child spacing counselling and service organized by the Society of Gynaecology and Obstetrics of Nigeria, North-East sector (SOGON-NE). The questionnaire inquired about knowledge, attitudes and practice of emergency contraception. Results: Eighty-nine $(89.0 \%)$ of the respondents were aware of EC and $88.0 \%$ have approved of its provision. The most common indication for the EC was unprotected sexual intercourse $(91.0 \%)$, followed by rape, failed contraception and missed pills. Sixty-five $(84.4 \%)$ of Nurse/Midwives and CHEWs were willing to provide EC for prospective clients and 59(76.6\%) of them had provided EC in the past. The commonest form of EC known to the respondents was Levonorgestrel (Postinor 2), followed by oral contraceptive pills (OCP) and intrauterine device (IUCD). Mifepristone and ulipristal were known to only $23.6 \%$ and $11.2 \%$ of the respondents respectively. Majority $(79.6 \%)$ will give EC immediately after intercourse. Only $46.1 \%$ of the respondent would institute EC within 7 days of unprotected intercourse and among them, 50\% were Nurse/Midwives and $46.4 \%$ were CHEWs. Conclusion: Both the knowledge and approval of EC among the HCWs in the IDP camps and host community clinics in Jere and Maiduguri metropolitan LGAs of Borno state are high. This can be harnessed to encourage the wide utilization of the EC by adolescents and other vulnerable womenin the IDP camps and Host communities.
\end{abstract}

Key words: Emergency contraceptive, Healthcare workers, Host community, IDP camps

\section{INTRODUCTION}

Emergency Contraction (EC) is a post-coital contraception method that gives women a second

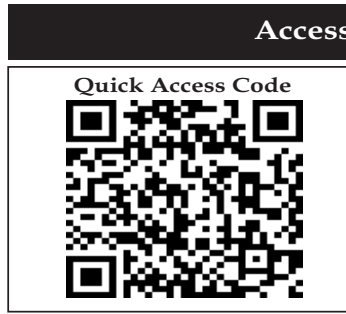

WEBSITE: www.kjmsmedicaljournal.com

DOI: $10.36020 /$ kjms.2021.1501.004 chance to avoid unintended pregnancy after failing to use a contraceptive before sexual intercourse or when contraception fails. ${ }^{1} \mathrm{EC}$ has the propensity to reduce the occurrence of unwanted pregnancies following unprotected sex, contraceptive malfunction and sexual assault which are common in the Internally Displaced Person (IDP) camps and host community. ${ }^{2,3}$ It is a safe, effective and relatively inexpensive way to prevent unintended pregnancy. ${ }^{1}$ 
The insurgency in Northeastern Nigeria has produced 1.93 million internally displaced women of reproductive age that require humanitarian assistance. ${ }^{2}$ These women have heightened health care needs because of the precarious condition in the camps and host community that makes them vulnerable to rape, sexual violence and other gender-based violence (GBV). ${ }^{2}$ A study showed that 6 out of 10 IDP women have experienced GBV. ${ }^{2}$ Also the women are at increased risk of unintended pregnancies and the consequent risk of unsafe abortion. To reduce this risk, the IDP must have access to family planning methods including EC.

Another challenge faced by the IDPs is the loss of their health posts and clinics with subsequent reliance on the IDP camp and host community clinics for their peculiar reproductive health needs. These needs include sexual education and family planning services that are essential for them to attain their optimum wellbeing and growth potentials. ${ }^{3}$ In one of the largest IDP camps in Borno state, 47 ladies with sexual violence-related pregnancies were seen in the IDP clinic in 2018 and all of them initially requested to terminate their pregnancies. ${ }^{4}$ Given the country's restrictive abortion law, they were counselled to keep the pregnancy but only $40 \%$ carried the pregnancy and delivered it in the camp clinic while the remaining were lost to follow up. ${ }^{4}$ Most of these women suffer intense stigmatization and other consequences of being unsupported single mothers. Their situation further worsens their vulnerability and sparks a cycle of repeated sexual exploitation, unintended pregnancies and unsafe abortions. Many of these pregnancies could have been avoided if the ladies were aware of and had access to EC in the camps and the knowledge, attitude and practice of the HCWs in the IDP camps towards EC is an important determinant of the utilization of the services by the clients that might require it.

A previous study conducted amongst HCWs in clinics across three LGAs in Borno State showed that a third of the Nurse/Midwives were not aware of EC and abysmal $36.2 \%$ of the HCWs ever provided EC to clients. ${ }^{5}$ The modest awareness and poor provision of the EC needs to be reviewed to address the knowledge gap. In addition, the study was conducted before the proliferation of the IDP camps and the consequent demographic shift in the Host communities heralded by the longstanding insurgency. A good attitude together with the availability of the commodities in the clinic, would substantially improve access to EC and reduce the occurrence of unintended pregnancies and unsafe abortions.

This study seeks to determine the knowledge, attitude and practice of EC amongst the HCWs working in IDP camps and host community clinics in Jere and Maiduguri Metropolitan Local government areas (LGAs) of Borno State, Nigeria.

\section{MATERIALS AND METHOD}

A self-administered, pretested questionnaires were instituted to $100 \mathrm{HCWs}$ from 20 Internally Displaced Persons (IDP) camps and host community clinics in Jere and Maiduguri metropolitan LGAs, Borno State on $20^{\text {th }}$, May 2019 and $27^{\text {th }}$ May 2019. The clinics were selected using simple random sampling across the two LGAs. The HCWs were in two groups of 50 attending a fiveday workshop on child spacing counselling and service for 'Scaling-up family planning uptake project' organized by the Society of Gynaecology and Obstetrics of Nigeria-Northeast (SOGON-NE) sector with the support of Saving One Million Lives (SOML) Borno State. The workshops held at the Conference Hall of the University of Maiduguri Teaching Hospital (UMTH), Maiduguri. The questionnaires were instituted on the first day of the training (before the commencement of the workshop). This was to assess their knowledge, attitude and practice of EC in IDP camps and host community clinics. Both open-ended and closedended questions were asked.

Respondents were asked to indicate if they were aware of EC and their attitude toward providing it for adolescents and young women. They were also asked to indicate if it was available in their clinic and they had ever provided or prescribed it. They were asked about the frequency of consultation or visit by clients seeking EC in the last 12 months and the various indications for the use of EC. They were also asked if they have had clients that approached them for abortion following an unintended pregnancy in the last 12 months. The biodata, cadre as HCW, level of education and years of experience were also explored.

The HCW comprise Nurse/Midwives, Community Health Extension Workers (CHEW) and Healthcare Mobilizers. The Healthcare Mobilizers were 
volunteers attached to the clinics and their function was to mobilize women from the communities and IDP camps to avail themselves for reproductive health services, particularly postnatal care, family planning and immunization.

The questionnaire was pre-tested with 10 other HCWs in Maiduguri that were not part of the study. For this study, the HCWs were categorized into Nurse/Midwives, CHEWs and Healthcare Mobilizers. The data was analyzed using SPSS version 20.0 (Chicago, IL, USA) for window statistical package. Analysis was carried out for descriptive statistics and illustrated as proportions and percentages. Chi-square or Fisher exact test at $95 \%$ confidence interval was done where appropriate. A P-value of less than 0.05 was considered statistically significant.

Ethical clearance was obtained from the ethical research committee of the UMTH and consent was implied as the participant completed the questionnaire voluntarily.

\section{RESULTS}

All the 100 questionnaires were completed and analyzed. Fourty-five $(45.0 \%)$ of the respondents were Nurses or Midwives, 32 (32.0\%) were community health extension workers (CHEWs) and $23(23.0 \%)$ were secondary school leavers that were attached to the IDP camp and host community clinics as Healthcare Mobilizers. Seventy-seven $(77.0 \%)$ of the respondents were family planning providers in the clinics.

The modal age group of the Nurse/Midwives and CHEWs was 30-39 years while that of the healthcare mobilizers was 20-29 years. About $26.0 \%$ of the Healthcare Mobilizers were teenagers compared to only $4.4 \%$ and $3.1 \%$ of the Nurse/Midwives and CHEWs respectively as shown in table 1 . Majority $(69.6 \%)$ of the Healthcare Mobilizers were less than 5 years as HCWs while the majority of the Nurse/Midwives and CHEWs $(91.1 \%$ and $87.5 \%$ respectively) have put more than 5 years in service. The respondents were predominantly Muslims. Majority (52.2\%) of the Healthcare Mobilizers were single while $46.7 \%$ of the Nurse/Midwives and $56.3 \%$ of the CHEWs were married as shown in table 1.
Eighty-nine $(89.0 \%)$ of the respondents were aware of EC and the indications for its use. The awareness was highest amongst the Nurse/Midwives and least amongst the Healthcare Mobilizers as shown in table 2. The most common indication of EC was unprotected sexual intercourse as alluded to by 81 $(91.0 \%)$ of the respondents, followed by its use after rape, failed contraception and missed pills as shown in table 2 . Only $11.8 \%$ of the Healthcare Mobilizers and $50.0 \%$ of the CHEWs knew that EC can be used by women that have missed their oral contraceptive pills to prevent unintended pregnancy.

Table 3 shows the knowledge of the time frame within which EC can be instituted after unprotected sexual intercourse. Majority $(79.6 \%)$ will give EC immediately after intercourse. Only $46.1 \%$ of the respondent could institute EC within 7 days of unprotected intercourse and among them were $50 \%$ of the Nurse/Midwives and $46.4 \%$ of the CHEWs studied.

The approval rate for EC among the respondents was $88(88 \%)$ and $69(69 \%)$ have had clients seeking EC in the past 12 months. Additionally, 75(75\%) of the respondents have had at least one client approach them to procure abortion for unintended pregnancy in the last 12 months.

Amongst the family planning providers (Nurse/Midwives and CHEWs only), 9.1\% had clients seeking EC at least once every week while $80.6 \%$ had women seeking EC once a month or less as shown in table 4 . Sixty-five $(84.4 \%)$ were willing to provide EC for prospective clients and 59(76.6\%) had provided EC in the past.

The commonest form of EC known to the respondents was Levonorgestrel (Postinor 2) as pointed out by $83(93.3 \%)$, followed by oral contraceptive pills (OCP) and intrauterine device (IUCD) as shown in table 5. In terms of additional formal training with certification since their last qualification, $77(77.0 \%)$ of the respondents have had additional family planning training either as workshops or refresher courses. But, only 10 out of the 20 clinics had EC available in their family planning units as indicated by the respondents. A secondary analysis showed that none of the IDP camp clinics had EC. 
Table 1: Sociodemographic Characteristics of the Respondents

\begin{tabular}{|c|c|c|c|c|c|}
\hline Characteristics & Nurse/midwives & CHEW & Mobilizers & $\begin{array}{l}\text { Chi-square/ } \\
\text { Fisher exact }\end{array}$ & $\begin{array}{l}\mathrm{P} \\
\text { Value } \\
\end{array}$ \\
\hline \multicolumn{6}{|l|}{ Age in Years } \\
\hline Less than 20 & $2(4.4)$ & $1(3.1)$ & $6(26.1)$ & 9.42 & 0.002 \\
\hline $20-29$ & $9(20.0)$ & $8(25.0)$ & $8(34.8)$ & 1.77 & 0.9 \\
\hline $30-39$ & $14(31.1)$ & $10(31.3)$ & $7(30.4)$ & 0.99 & 0.96 \\
\hline $40-49$ & $11(24.5)$ & $9(28.1)$ & $2(8.7)$ & 1.60 & 0.21 \\
\hline 50 or more & $9(20.0)$ & $4(12.5)$ & $0(0.0)$ & 5.28 & 0.022 \\
\hline Total & $45(100)$ & $32(100)$ & $23(100)$ & - & - \\
\hline $\begin{array}{l}\text { Years in Practice } \\
\text { less than } 5\end{array}$ & $4(8.9)$ & $4(12.5)$ & $16(69.6)$ & 25.92 & $<0.001$ \\
\hline $5-10$ & $13(28.9)$ & $12(37.5)$ & $6(26.1)$ & 0.34 & 0.24 \\
\hline $11-15$ & $11(24.4)$ & $6(18.8)$ & $1(4.4)$ & 4.18 & 0.05 \\
\hline $16-20$ & $9(20.0)$ & $5(15.6)$ & $0(0.0)$ & 4.16 & 0.032 \\
\hline 21 or more & $8(17.8)$ & $5(15.6)$ & $0(0.0)$ & 3.70 & 0.054 \\
\hline Total & $45(100)$ & $32(100)$ & $23(100)$ & - & - \\
\hline $\begin{array}{l}\text { Religion } \\
\text { Christianity }\end{array}$ & $19(42.2)$ & $9(28.1)$ & $6(26.1)$ & 9.62 & 0.008 \\
\hline Muslim & $26(57.8)$ & $23(71.9)$ & 17(73.9) & 0.85 & 0.66 \\
\hline Total & $45(100)$ & $32(100)$ & $23(100)$ & - & - \\
\hline $\begin{array}{l}\text { Marital status } \\
\text { Married }\end{array}$ & $21(46.7)$ & $18(56.3)$ & $9(39.1)$ & 2.60 & 0.27 \\
\hline Single & $15(33.3)$ & $8(25.0)$ & $12(52.2)$ & 2.88 & 0.24 \\
\hline Widowed & $9(20.0)$ & $6(18.7)$ & $2(8.7)$ & 1.23 & 0.54 \\
\hline Total & $45(100)$ & $32(100)$ & $23(100)$ & - & - \\
\hline
\end{tabular}

Table 2: Awareness of EC and knowledge of its indications for use among the HCWs

\begin{tabular}{|c|c|c|c|c|c|c|}
\hline Variable & $\begin{array}{l}\text { Nurse/midwives } \\
(\mathrm{n}, \%)\end{array}$ & $\begin{array}{l}\text { CHEW } \\
(n, \%)\end{array}$ & $\begin{array}{l}\text { Health Mobilizers } \\
(\mathrm{n}, \%)\end{array}$ & $\begin{array}{l}\text { Total } \\
(\mathrm{n}, \%)\end{array}$ & $\begin{array}{l}\text { Fisher } \\
\text { exact }\end{array}$ & $\begin{array}{l}\mathbf{P} \\
\text { Value }\end{array}$ \\
\hline $\begin{array}{r}\text { Aware of EC } \\
\text { Yes } \\
\text { No } \\
\text { Total }\end{array}$ & $\begin{array}{l}44(97.8) \\
1(2.2) \\
45(100)\end{array}$ & $\begin{array}{l}28(87.5) \\
4(12.5) \\
32(100)\end{array}$ & $\begin{array}{l}17(73.9) \\
6(26.1) \\
23(100)\end{array}$ & $\begin{array}{l}89(89.0) \\
11(11.0) \\
100(100)\end{array}$ & 8.96 & 0.011 \\
\hline $\begin{array}{r}\text { Unprotected Sex } \\
\text { Yes } \\
\text { No }\end{array}$ & $\begin{array}{l}44(100) \\
0(0.0) \\
0(0.0)\end{array}$ & $\begin{array}{l}25(89.3) \\
2(7.1) \\
1(3.6)\end{array}$ & $\begin{array}{l}12(70.6) \\
2(11.8) \\
3(17.6)\end{array}$ & $\begin{array}{l}81(91.0) \\
4(4.5) \\
4(4.5)\end{array}$ & $\begin{array}{l}9.83 \\
4.62 \\
5.22\end{array}$ & $\begin{array}{l}0.0001 \\
0.09 \\
0.04\end{array}$ \\
\hline $\begin{array}{c}\text { Rape } \\
\text { Yes } \\
\text { No } \\
\text { Don't know }\end{array}$ & $\begin{array}{l}42(95.6) \\
1(2.3) \\
1(2.3)\end{array}$ & $\begin{array}{l}25(89.3) \\
2(7.1) \\
1(3.6)\end{array}$ & $\begin{array}{l}10(58.8) \\
4(23.5) \\
3(17.7)\end{array}$ & $\begin{array}{l}77(86.5) \\
7(7.9) \\
5(5.6)\end{array}$ & $\begin{array}{l}14.37 \\
7.68 \\
5.79\end{array}$ & $\begin{array}{l}0.008 \\
0.02 \\
0.03\end{array}$ \\
\hline $\begin{array}{c}\text { Failed contraceptives } \\
\text { Yes } \\
\text { No } \\
\text { Don't know }\end{array}$ & $\begin{array}{l}34(77.2) \\
5(11.4) \\
5(11.4)\end{array}$ & $\begin{array}{l}18(64.3) \\
4(14.3) \\
6(21.4)\end{array}$ & $\begin{array}{l}4(23.5) \\
8(47.1) \\
5(29.4)\end{array}$ & $\begin{array}{l}56(62.9) \\
17(19.1) \\
16(18.0)\end{array}$ & $\begin{array}{l}15.21 \\
10.72 \\
3.04\end{array}$ & $\begin{array}{l}<0.001 \\
0.01 \\
0.20\end{array}$ \\
\hline $\begin{array}{c}\text { Missed pills } \\
\text { Yes } \\
\text { No } \\
\text { Don't know }\end{array}$ & $\begin{array}{l}26(591 .) \\
10(22.7) \\
8(18.2)\end{array}$ & $\begin{array}{l}14(50.0) \\
8(28.6) \\
6(21.4)\end{array}$ & $\begin{array}{l}2(11.8) \\
8(47.1) \\
7(41.1)\end{array}$ & $\begin{array}{l}42(47.2) \\
26(29.2) \\
21(23.6)\end{array}$ & $\begin{array}{l}11.15 \\
3.52 \\
3.70\end{array}$ & $\begin{array}{l}0.01 \\
0.16 \\
0.20\end{array}$ \\
\hline
\end{tabular}


Table 3: knowledge of the timing of Emergency Contraceptive

\begin{tabular}{cllllll}
\hline $\begin{array}{l}\text { The acceptable } \\
\text { timing of EC }\end{array}$ & $\begin{array}{l}\text { Nurse/ } \\
\text { midwives (n, \%) }\end{array}$ & $\begin{array}{l}\text { CHEW } \\
(\mathrm{n}, \%)\end{array}$ & $\begin{array}{l}\text { Healthcare } \\
\text { Mobilizers (n, \%) }\end{array}$ & $\begin{array}{l}\text { Total } \\
(\mathrm{n}, \%)\end{array}$ & Chi-square & $\begin{array}{l}\mathrm{P} \\
\text { Value }\end{array}$ \\
\hline Immediately & $44(97.8)$ & $30(93.8)$ & $13(56.5)$ & $87(87.0)$ & 0.35 & 0.84 \\
Within 72 hours & $38(84.4)$ & $21(65.6)$ & $10(43.5)$ & $69(69.0)$ & 0.51 & 0.50 \\
Within 7 days & $28(62.2)$ & $13(40.6)$ & $6(26.1)$ & $47(47.0)$ & 0.42 & 0.81 \\
Anytime & $6(13.3)$ & $5(15.6)$ & $8(34.8)$ & $19(19.0)$ & 3.63 & 0.16 \\
\hline
\end{tabular}

*The sum is more than 100 because of multiple response.

Table 4: Approval and provision of Emergency Contraceptives amongst Nurse/Midwives and CHEWs.

\begin{tabular}{rlll}
\hline Variable & Nurse/Midwives $(\mathrm{n}, \%)$ & CHEW $(\mathrm{n}, \%)$ & Total (n, \%) \\
\hline Approve of EC & & & \\
Yes & $42(93.3)$ & $28(87.5)$ & $70(90.1)$ \\
No & $3(6.7)$ & $4(12.5)$ & $7(9.9)$ \\
Total & $45(100)$ & $32(100)$ & $77(100)$
\end{tabular}

Can you provide EC

Fischer exact $=0.76, \mathbf{p}=0.38$

$\begin{array}{clcc}\text { Yes } & 40(88.9) & 25(78.1) & 65(84.4) \\ \text { No } & 5(11.1) & 7(21.9) & 12(15.6) \\ \text { Total } & 45(100) & 32(100) & 77(100) \\ & & \chi^{2}=1.63, \mathbf{p}=0.20 & \end{array}$

Ever had Clients seeking EC

$\begin{array}{clll}\text { Yes } & 42(93.3) & 27(84.4) & 69(89.6) \\ \text { No } & 3(6.7) & 5(15.6) & 8(10.4) \\ \text { Total } & 45(100) & 32(100) & 77(100)\end{array}$

Frequency of clients seeking EC

Fischer exact $=1.59, \mathrm{p}=0.21$

$\begin{array}{clll}\text { Every week } & 5(11.1) & 2(6.3) & 7(9.1) \\ \geq \text { once a month } & 23(51.1) & 15(48.8) & 38(49.4) \\ \text { < once a month } & 14(31.1) & 10(31.3) & 24(31.2) \\ \text { Not applicable } & 3(6.7) & 5(15.6) & 8(10.3) \\ \text { Total } & 45(100) & 32(100) & 77(100)\end{array}$

Ever Provided EC

Fischer exact $=2.00, \mathrm{p}=0.57$

$\begin{array}{cccc}\text { Yes } & 37(82.2) & 22(68.8) & 59(76.6) \\ \text { No } & 8(17.8) & 10(31.3) & 18(23.4) \\ \text { Total } & 45(100) & 32(100) & 77(100) \\ & & \chi^{2}=1.87, \mathbf{p}=0.17\end{array}$

NB: Only the Nurses/Midwives and CHEWs can provide EC in the clinics. 
Table 5: Type of Emergency Contraceptives known to the respondents

\begin{tabular}{lllllll}
\hline Cadre/type of EC & Postinor 2 & OCP & IUCD & Danazol & Mifepristone & Ulipristal \\
\hline Nurses/Midwives & $42(95.5)$ & $40(90.1)$ & $34(72.3)$ & $17(38.6)$ & $4(9.1)$ & $2(4.5)$ \\
CHEW & $26(92.9)$ & $21(75.0)$ & $18(64.3)$ & $8(28.6)$ & $1(3.6)$ & $0(0.0)$ \\
Health Mobilizers & $15(88.2)$ & $9(52.9)$ & $2(11.8)$ & $0(0.00$ & $0(0.0)$ & $0(0.0)$ \\
Total & $83(93.3)$ & $70(78.7)$ & $54(60.7)$ & $37(41.6)$ & $21(23.6)$ & $10(11.2)$ \\
\hline
\end{tabular}

\section{DISCUSSION}

Emergency contraception awareness among the healthcare workers (HCW) in IDP camp and host community clinics in Jere and Maiduguri Metropolitan LGAs of Borno State is high (89.0\%). However, it is still short of $100 \%$ expected given the obvious need for the drugs in their various places of work. Recent studies amongst medical doctors and other health professionals showed an awareness of $100 \%$. $^{6-8}$

The EC awareness of $89.0 \%$ from this study is an improvement from a previous report by Geidam and colleagues who sampled HCWs across three LGAs in Borno state about 10 years ago. ${ }^{5}$ This improved knowledge and awareness may be because the majority of the HCWs have put in a reasonable number of years in service to be grounded in family planning. In addition, our respondents were majorly family planning providers and some even had additional family planning training $(77.0 \%)$ after graduation. Besides knowledge, most of the respondents were aware of the correct timing of administration of EC, as $87 \%$ would offer the EC immediately after unprotected intercourse. This also showed a remarkable improvement from $51 \%$ about a decade ago. ${ }^{5}$ Our EC awareness rate is much higher than the $68.3 \%$ reported by Najafi-Sharjabad et al among HCW in Iran. ${ }^{9}$ The difference may not be unconnected to the fact that most of the HCWs we studied have had additional family planning training as alluded above. Byamugisha et al also reported a higher knowledge on EC among HCWs that have had additional family planning training or update course in the last year. ${ }^{10}$ Regular updates and workshops are essential to keep the HCWs abreast of development in their area of practice.

Levonorgestrel is the commonest EC provided by the HCWs studied. A systematic review has affirmed the tolerability, safety and effectiveness of this method. ${ }^{11}$ Mifepristone and ulipristal were known to only $23.6 \%$ and $11.2 \%$ of the respondents respectively. This finding is not unexpected because these methods are not widely available in Nigeria. In addition, some HCWs believed that mifepristone is an abortifacient and have reservations about prescribing it to their clients. ${ }^{9,12}$ Only $9.8 \%$ of family planning providers in Turkey also mentioned mifepristone as an EC pill. ${ }^{8}$ Similar to our finding, Tshitenge et also found a lack of knowledge of newer methods of EC among HCW in Botswana. ${ }^{13}$ Regular continuing medical education and update on the medical practice will be useful in filling up the knowledge gap.

The IDPs have a peculiar healthcare need. A recent qualitative study by Odo and colleagues found that sexuality education, family planning and safe motherhood services are the important sexual and reproductive health needs of the IDPs in Borno state. ${ }^{3}$ Also, this study showed that $75 \%$ of the respondents have had clients approach them with unintended pregnancies seeking an abortion. These pregnancies could have been prevented if the clients had used EC soon after the sexual encounter. Studies have shown a direct relationship between the non-utilization of contraceptive and the rate of unintended pregnancies. ${ }^{14,15}$ To improve access to the EC, there is a need to make the commodity available for clients by stocking the family planning units as none of the IDP camp clinics had EC at the time of the study. Government and NGOs should provide more EC to various camps for IDPs to use. Furthermore, the HCWs demonstrated high approval and a positive attitude as most of the respondents were willing to provide EC to their clients. The approval rate of $90.1 \%$ in this study is similar to the approval rate of $94.9 \%$ reported by Shaki et al in Tanzania. ${ }^{16}$ It is, however, much higher than $50 \%$ reported in Iran ${ }^{9}$ and $47 \%$ in Pakistan. ${ }^{12}$ It is important to harness the high approval and provision by HCWs in our study to encourage wide 
utilization of the EC in IDP camps and host communities.

Our study showed high demand for the EC in the IDP camps and host communities as $69.0 \%$ of the respondents have had clients demand EC in the previous one year with a frequency of at least once every week as volunteered by $7.4 \%$ of the respondents. These ladies may end up with unintended pregnancies unless they are offered EC in good time. A study on abortions in Nigeria showed that more than $56 \%$ of unintended pregnancies end up with induced abortion and its consequent morbidities. ${ }^{17}$ It is estimated that 285,000 of women that procured criminal abortion experienced serious health consequences and did not receive the optimum treatment they needed. ${ }^{17}$

Sadly, up to $40-50 \%$ of maternal mortality in Nigeria have been linked to complications of induced abortion each year. ${ }^{18}$ Illegal abortions are still common despite the restrictive Nigerian abortion law. ${ }^{17,18}$

Provision of EC and increased access to it by adolescent and young women will go a long way in curtailing the menace of criminal abortion. Metaanalysis has shown that provision of EC can improve utilization and shorten the time lag between unprotected intercourse and administration of EC amongst adolescents. ${ }^{19}$ The provision of EC brought about a fall in pregnancy rate even when no change in sexual behaviour was noted among the women. ${ }^{19}$ The HCWs should also offer youth-friendly services that will encourage contraception seeking among sexually active girls especially the vulnerable groups like IDPs and school girls. ${ }^{20,21}$ Based on their training, most of family planning providers can comfortably counsel adolescents for family planning. ${ }^{13}$

Aside from making the EC available, there is also the need to create awareness and improve healthseeking behaviour amongst the camp dwellers and women living in the host communities. This will ensure that they avail themselves for family planning services at the clinics. The use of Healthcare Mobilizers and peer educators amongst IDPs can be employed for behavioural modification in the camps. This is one of the modalities used by SOGON-NE and other NGOs to improve healthseeking behaviour in some of the IDP camps.

\section{REFERENCES}

1. Trussell J, Koenig J, Ellertson C, Stewart F. Preventing unintended pregnancy: the costeffectiveness of three methods of emergency contraception. Am J Public Health. 1997 Jun; 87(6): 932-937.

2. UNFPA. Nigeria Humanitarian Emergency report 2016. Available on https://www.unfpa.org/data/emergencies/nig eria-humanitarian-emergency (accessed 10th May 2020)

3. Odo AN, Musa K, Oladugba AV. Sexual and Reproductive Health Needs and Problems of Internally Displaced Adolescents (IDAs) in Borno State, Nigeria: A Mixed Method Approach. African Journal of Reproductive Health March 2020; $24 \quad(1): 87-96$. D O I : 10.29063/ajrh2020/v24i1.9.

4. Oladeji O, Oladeji B, Chamla D, Safiyanu G, Mele S, M s heli a H, A g b or J. S e x u a 1 Violence-Related Pregnancy Among Internally Displaced Women in an Internally Displaced Persons Camp in Northeast Nigeria. Journal of Interpersonal violence 2018 Aug 10:886260518792252.

5. Geidam AD, Kullima AA, Sadiq GU. International Journal of Health Research 2009; 2(4):339-346

6. Sunil Kumar KS, Hoblidar S. Emergency contraception, a study on knowledge, attitude and practice among gynecologists. Int J Reprod Contracept Obstet Gynecol 2016 ; $5(1) ; 198-201$. D O I : http://dx.doi.org/10.18203/23201770.ijrcog20151624

7. Oriji VK, Omietimi JE. Knowledge, attitude and practice of emergency contraception among medical doctors in Port Hartcourt. Niger J Clin Pract 2011;14(4):428-31.

8. Bildircin M, Sahin NH. Knowledge, attitudes and practices regarding emergency contraception among familyplanning providers in Turkey. Eur J Contracept Reprod Health Care 2005;10(3):151-156.

9. Najafi-Sharjabad F, Hajivandi A, Rayani M. Knowledge, attitude, and practice about Emergency Contraception among health 
staff in Bushehr state, south of Iran. Global Journal of Health Science 2014; 6(1): 52-60. https://doi.org/10.5539/gihs.v6n1p52.

10. Byamugisha JK, Mirembe FM, Faxelid E, Gemzell-Danielsson K. Knowledge, attitudes and prescribing pattern of emergency contraceptives by health care workers in Kampala, Uganda. Acta Obstetricia et Gynecologica. 2007; 86: 11111116.

11. Leelakanok N, Methaneethorn J. A Systematic Review and Meta-analysis of the Adverse Effects of Levonorgestrel Emergency Oral Contraceptive. Clinical Drug Investigation 2020;40:395-420. https://doi.org/10.1007/s40261-02000901-

12. Mir AS, Malik R. Emergency contraceptive pills: Exploring the knowledge and attitudes of community health workers in a developing muslim country. North Am J Med Sci 2010; 2:359-364.

13. Tshitenge ST, Nlisi K, Setlhare V, Ogundipe R. Knowledge, attitudes and practice of healthcare providers regarding contraceptive use in adolescence in Mahalapye, Botswana, South African Family Practice 2018; 60(6): 181-186. DOI: 10.1080/20786190.2018.1501239

14. Sarvestani KS, Ahmadi A, Enayat H, Movahed M. Level and Factors Related to Unintended Pregnancy with a Brief Review of New Population Policies in Iran. Iran J Public Health 2017; 46(7): 973-981

15. Abraha D, Welu G, Berwo M, Gebretsadik M, Tsegay T, Gebreheat G, Gebremariam H. Knowledge of and Utilization of Emergency Contraceptive and Its Associated Factors among Women Seeking Induced Abortion in Public Hospitals, Eastern Tigray, Ethiopia, 2017: A Cross-Sectional Study. Bio
Med Research International 2019; 7209274: 1-7. https://doi.org/10.1155/2019/7209274

16. Shaki MH. knowledge, attitude and practices of Emergency Contraceptives among health care providers and medical students in Dar Es salam. Muhimbili University of Health and Allied Sciences (MUHAS). 2010.

17. Bankole A, Adewole IF, Hussain R, Awolude O, Singh S, Akinyemi JO. The Incidence of Abortion in Nigeria. Int Perspect Sex Reprod Health 2015; 41(4): 170-181. doi:10.1363/4117015

18. Government of the Federal Republic of Nigeria. Nigeria Millennium Development Goals Report 2010. Abuja, Nigeria: Government of the Federal Republic of Nigeria; 2010.

19. Kyungsoon R, Misoon L, Younghae K, Seonhwa B, Mihyang C. How Does Advance Provision of Emergency Contraceptives Affect Contraceptive Use and Sexual Activity Among Adolescents? Systematic Review and Meta-Analysis. J Korean Acad Nurs 2018; 48(3): 255-265.

20. Isa B, Ibrahim SM, Kulllima AA, Bako B. Awareness and utilization of emergency contraceptives among undergraduates in a Nigerian University. Trop J Obstet Gynaecol 2016; 33: 196-200.

21. Babatunde OA, Ibirongbe DO, Omede O, Babatunde OO, Durowade KA, Saludeen AG, Akande TM. Knowledge and use of emergency contraception among students of public secondary school in Ilorin, Nigeria. Pan African Medical Journal $2016 ; 23: 74$. a v a i 1 a ble o n https / / w w w panafrican-medjournal.com/content/article/23/74/full (accessed 20/08/2020).

Cite this article as: Babagana Bako, Bala Mohammed Audu, Mohammed Bello Kawuwa, Asta Mana, Anna Peter. Knowledge, Attitude and Practice of Emergency Contraception

Amongst Healthcare Workers in IDP Camps and Host Community Clinics in Jere and Maiduguri Metropolitan Local Government Areas, Borno State.KJMS 2021; 15(1): 27 - 34. 